\title{
Effects of Exercise Training on Anabolic and Catabolic Hormones with Advanced Age: A Systematic Review
}

\author{
Hassane Zouhal ${ }^{1,2}$ (1) Ayyappan Jayavel ${ }^{3} \cdot$ Kamalanathan Parasuraman $^{3} \cdot$ Lawrence D. Hayes $^{4} \cdot$ Claire Tourny $^{5}$. \\ Fatma Rhibi ${ }^{1} \cdot$ Ismail Laher $^{6} \cdot$ Abderraouf Ben Abderrahman $^{7} \cdot$ Anthony C. Hackney ${ }^{8}$
}

Accepted: 21 November 2021 / Published online: 22 December 2021

(c) Crown 2021

\begin{abstract}
Background Ageing is accompanied by decreases in physical capacity and physiological regulatory mechanisms including altered hormonal regulation compared with age-matched sedentary people. The potential benefits of exercise in restoring such altered hormone production and secretion compared to age-matched physically inactive individuals who are ageing remains unclear.

Objectives The aim of this systematic review was to summarise the findings of exercise training in modulating levels of ostensibly anabolic and catabolic hormones in adults aged $>40$ years.

Methods We searched the following electronic databases (to July 2021) without a period limit: Cochrane Library, PubMed, Science Direct, Scopus, SPORTDiscus and Web of Science. Additionally, a manual search for published studies in Google Scholar was conducted for analysis of the 'grey literature' (information produced outside of traditional commercial or academic publishing and distribution channels). The initial search used the terms 'ageing' OR 'advanced age' OR 'old people' OR ‘older' OR elderly' AND ‘anabolic hormones' OR ‘catabolic hormones' OR ‘steroid hormones' OR 'sex hormones' OR 'testosterone' OR 'cortisol' OR 'insulin' OR 'insulin-like growth factor-1' OR 'IGF-1' OR 'sex hormone-binding globulin' OR 'SHBG' OR 'growth hormone' OR 'hGH' OR 'dehydroepiandrosterone' OR 'DHEA' OR 'dehydroepiandrosterone sulfate (DHEA-S)' AND 'exercise training' OR 'endurance training' OR 'resistance training' OR 'strength training' OR 'weight-lifting' OR 'high-intensity interval training' OR 'high-intensity interval exercise' OR 'high-intensity intermittent training' OR 'high-intensity intermittent exercise' OR 'interval aerobic training' OR 'interval aerobic exercise' OR 'intermittent aerobic training' OR 'intermittent aerobic exercise' OR 'high-intensity training' OR 'high-intensity exercise' OR 'sprint interval training' OR 'sprint interval exercise' OR 'combined exercise training' OR 'anaerobic training'. Only eligible full texts in English or French were considered for analysis.

Results Our search identified 484 records, which led to 33 studies for inclusion in the analysis. Different exercise training programs were used with nine studies using endurance training programs, ten studies examining the effects of high-intensity interval training, and 14 studies investigating the effects of resistance training. Most training programs lasted $\geq 2$ weeks. Studies, regardless of the design, duration or intensity of exercise training, reported increases in testosterone, sex hormonebinding globulin (SHBG), insulin-like growth factor-1 (IGF-1), human growth hormone (hGH) or dehydroepiandrosterone (DHEA) (effect size: $0.19<d<3.37$, small to very large) in both older males and females. However, there was no consensus on the effects of exercise on changes in cortisol and insulin in older adults.

Conclusion In conclusion, findings from this systematic review suggest that exercise training increases basal levels of testosterone, IGF-1, SHBG, hGH and DHEA in both male and females over 40 years of age. The increases in blood levels of these hormones were independent of the mode, duration and intensity of the training programs. However, the effects of long-term exercise training on cortisol and insulin levels in elderly people are less clear.
\end{abstract}

\section{Introduction}

Abderraouf Ben Abderrahman and Anthony C. Hackney are equal last authors.

Extended author information available on the last page of the article
Ageing is characterized by decreases in physical capacity that are related to a loss of muscle mass and decreased muscle contraction velocity [1] and maximum strength, which 


\section{Key Points}

For basal concentrations of ostensibly anabolic hormones, exercise training produced trivial to very large increases in testosterone, small to moderate increases in insulin-like growth factor-1 (IGF-1), small to very large increases in human growth hormone (hGH), trivial to very large increases in insulin, and small to large increases in dehydroepiandrosterone sulphate (DHEA-S) in adults aged $>40$ years.

Small to large increases were observed for basal sex hormone-binding globulin (SHBG).

For the ostensibly catabolic hormone cortisol, effects ranged from a small decrease to a very large increase. Moderate effects and large effects were observed for the other corticosteroids cortisone and corticosterone, respectively.

Observed alterations to the hormonal mileu were not readily related to participant age or acute training programme variables, or chronic training variables (e.g. intensity, volume, frequency).

accelerate in particular after 50 years of age [2, 3]. According to Korhonen et al. [4], strength and muscle volume peaks around $~ 30$ years of age and decreases by $15 \%$ per decade from age 50 onwards, until 70 years of age, when strength is $~ 30 \%$ of that of a 30 -year-old $[5,6]$. This decrease in muscle strength is due in large part to decreases in the contractile properties of muscle [5, 7], especially in the number of fasttwitch type II muscle fibers $[5,8,9]$.

Loss of physical function and hormonal status are important determinants of health and longevity in older adults [10-13]. Concentrations of anabolic hormones are altered with advancing age, as shown by yearly $1 \%$ decreases in testosterone in about $50 \%$ of men $\geq 30$ years of age (from peak values at 20 years of age) [14], suggesting changes in anabolic hormones start from the fourth decade of life $[15,16]$. The fall in blood testosterone levels during ageing diminishes its anabolic effects in skeletal muscle, and so negatively impacts neuromuscular performance [17], muscle mass and bone mineral density [18].

Ageing alters metabolism and degradation of hormones, especially in those individuals with decreased liver or kidney function [19]. In addition, ageing reduces target cell hormone receptor number, affinity and signal transduction $[20,21]$. Moreover, anabolic hormones such as testosterone inhibit the secretion of cortisol, diminishing glucocorticoid-mediated catabolism of skeletal muscle, meaning testosterone has both anabolic and anti-catabolic effects [22-24]. Nearly $98 \%$ of circulating testosterone is bound to sex hormone-binding globulin (SHBG) and albumin [25], both of which are also altered by the ageing process [26]. As the concentration of SHBG increases with age, the level of free (unbound) and bioavailable (bound loosely to albumin) testosterone decreases, so that there is less testosterone available for tissue uptake [27]. Interestingly, there are similar patterns of androgenic hormone decline (andropause) and somatrotropic hormone decline (somatopause); the latter also have anabolic actions [14]. Specifically, human growth hormone (hGH) and its main downstream protein, insulin-like growth factor-1 (IGF-1), decrease with advanced age [14]. Secretion of hGH decreases by $14 \%$ per decade after 20 years of age [14], and reaches, by the age of $\sim 60$ years, half of the hGH secretion of younger counterparts (20-30 years) [28]. The main stimulated protein downstream of hGH, IGF-1, as already noted, also decreases with age ( $\sim 10 \%$ per decade) [28]. IGF-1 is also anabolic in nature, increases cell proliferation, cell differentiation and energy metabolism, and prevents apoptosis [29].

Although endocrine dysregulation is associated with advanced age, it is difficult to attribute this alteration to age exclusively, as physical activity and exercise also influence the hormonal mileu [19]. Age is associated with physical inactivity [30], which can influence the age-endocrine dysregulation relationship. While ageing per se may not cause endocrinological dysregulation, age-associated increases in sedentary behaviour could [31-34]. Exercise is a nonpharmacological strategy to counteract come of the physiological changes that occur with age, including endocrine changes [19, 35-40].

Exercise exerts well-known health-promoting cardioprotective effects [41], with recent meta-analytical evidence demonstrating running activities were associated with a $30 \%$ reduction in cardiovascular mortality [42]. This emphasizes the importance of physical activity for health, supporting the recent narrative by the UK government that identified a curvilinear dose-response relationship between physical activity and health outcomes [43]. Moreover, several reports or opinion pieces suggest exercise may be a countermeasure to human biological ageing [44]. Thus, exercise and physical activity ameliorate many deleterious effects of chronological ageing on multiple physiological systems. There are some reports that lifelong exercisers are more phenotypically younger in terms of endocrinological profile than their sedentary counterparts, and exercise interventions result in a 'younger' hormonal profile than before undertaking exercise [45]. Therefore, it appears consistent physical exercise may be required to maintain endocrine function with ageing. However, before exercise can be proposed as a viable countermeasure to endocrinological dysregulation, it is important to consider the existing literature in terms of methodologies, 
quality of research and heterogeneity, and conduct a systematic review of available literature. To the best of our knowledge, only one narrative review [19] and two book chapters $[46,47]$ have reviewed the effects of physical exercise on changes in anabolic and catabolic hormones in older adults. Therefore, it seemed prudent to conduct a systematic review of the effects of various exercise training protocols on ostensibly anabolic and catabolic hormones in people aged $>40$ years with normal body mass.

\section{Methods}

\subsection{Eligibility Criteria}

Population, Intervention, Comparison, Outcome and Study design (PICOS) criteria were used for inclusion of studies in this review (see Table 1) [48]. This systematic review included original studies (randomized or non-randomized) for which the full texts were available and that performed interventions with exercise training, included 2 or more weeks of follow-up, and involved subjects who were aged between 40 and 85 years. We included studies that involved one or both sexes, and specifically evaluated blood levels of any of the following hormones: total testosterone, cortisol, insulin, IGF-1, SHBG, hGH, dehydroepiandrosterone (DHEA) and dehydroepiandrosterone sulfate (DHEA-S) before and after exercise.

Duplicate publications or sub-topics of included studies [e.g., studies involving co-morbidities or pathologies, and studies linking exercise to nutritional interventions (e.g., nutrition counselling, balanced or hypocaloric diets, and supplements)] or pharmacological agents were all excluded to reduce confounding factors [49]. Studies involving individuals with overweight or obese BMIs (BMI $\geq 25 \mathrm{~kg} / \mathrm{m}^{2}$ ] were also excluded [49].

\subsection{Literature Search Strategy}

This systematic review is reported in accordance with the Preferred Reporting Items for Systematic Reviews and MetaAnalyses (PRISMA) statement and the Cochrane Handbook for Systematic Reviews of Interventions [50]. The study protocol was registered (CRD42019138269) in the International Prospective Register of Systematic Reviews (PROSPERO) platform.

We searched the following electronic databases (to July 2021) without a period limit: Cochrane Library, PubMed, Science Direct, Scopus, SPORTDiscus and Web of Science. Additionally, a manual search for published studies in Google Scholar was conducted for analysis of the 'grey literature' (information produced outside of traditional commercial or academic publishing and distribution channels). The initial search used the terms 'ageing' OR 'advanced age' OR 'old people' OR 'older' OR elderly' AND 'anabolic hormones' OR 'catabolic hormones' OR 'steroid hormones' OR 'sex hormones' OR 'testosterone' OR 'cortisol' OR 'insulin' OR 'insulin-like growth factor-1' OR 'IGF-1' OR 'sex hormone-binding globulin' OR 'SHBG' OR 'growth hormone' OR 'hGH' OR 'dehydroepiandrosterone' OR 'DHEA' OR 'dehydroepiandrosterone sulfate (DHEA-S)' AND 'exercise training' OR 'endurance training' OR 'resistance training' OR ' strength training' OR 'weight-lifting' OR 'high-intensity interval training' OR 'high-intensity interval exercise' OR 'high-intensity intermittent training' OR 'high-intensity intermittent exercise' OR 'interval aerobic training' OR 'interval aerobic exercise' OR 'intermittent aerobic training' OR 'intermittent aerobic exercise' OR 'high-intensity training' OR 'high-intensity exercise' OR 'sprint interval training' OR 'sprint interval exercise' OR 'combined exercise training' OR 'anaerobic training'. Only eligible full texts in English or French were considered for analysis.

\subsection{Study Selection and Data Extraction}

Three authors independently performed searches in the electronic databases, and disagreements were resolved by consensus. The literature search strategies used for all databases are available in the supporting information.

The data-collection process is shown in Fig. 1 [51]. Titles and abstracts of selected articles were independently assessed by two researchers (HZ and $\mathrm{AJ}$ ). The reviewers were not blinded to the authors, institutions or journals associated with the studies. Abstracts that provided insufficient information on inclusion and exclusion criteria were
Table 1 PICOS (participants, interventions, comparisons, outcomes, study design)

\begin{tabular}{ll}
\hline PICOS component & Details \\
\hline Participants & Healthy humans aged: $>40$ and $<85$ years \\
Interventions & Exercise training with two or more weeks of follow-up \\
Comparisons & Control group/Untrained participants \\
Outcomes & Physical performances, anabolic/catabolic hormone responses \\
Study designs & nRCTs, nRnCTs and RCTs \\
\hline
\end{tabular}

$n R C T$ non-randomized controlled trial, $n R n C T$ non-randomized non-controlled trial, $R C T$ randomized controlled trial 
retrieved for full-text analysis. Furthermore, the researchers independently analysed the full text and determined the eligibility of the studies, and disagreements were resolved by consensus. The agreement rate between the reviewers was $97 \%$ for the eligibility criteria of the study.

Corresponding authors of publications were contacted to avoid duplicate-counting of participants or to clarify questions about the methods where necessary. The corresponding authors were also contacted to provide data that may not have been included in the publications. Two researchers $(\mathrm{HZ}$ and $\mathrm{AJ})$ independently performed the data extraction, and disagreements were resolved by consensus. Data were extracted for pre- and post-training hormone levels.

\subsection{Assessment of Risk of Bias}

The quality of studies was assessed using the Physiotherapy Evidence Database (PEDro) scale (http://www.pedro. fhs.usyd.edu.au), which has good reliability and validity [52]. The PEDro scale has 11 possible points that examine external validity (criterion 1) and internal validity (criteria 2-9) of controlled trials, and also enable determination of whether there was sufficient statistical information for interpreting results (criteria 10-11). The items of the scale are: (1) eligibility criteria were specified; (2) subjects were randomly allocated to groups; (3) allocation was concealed; (4) groups were similar at baseline; (5) subjects were blinded; (6) therapists who administered the treatment were blinded; (7) assessors were blinded; (8) measures of key outcomes were obtained from more than $85 \%$ of subjects; (9) data were analysed by intention to treat; (10) statistical comparisons between groups were conducted; and (11) point measures and measures of variability were provided. The first criterion is not included in the final score. Moreover, because of the nature of the physical activity interventions, where patient and therapy blinding and allocation are unlikely, the

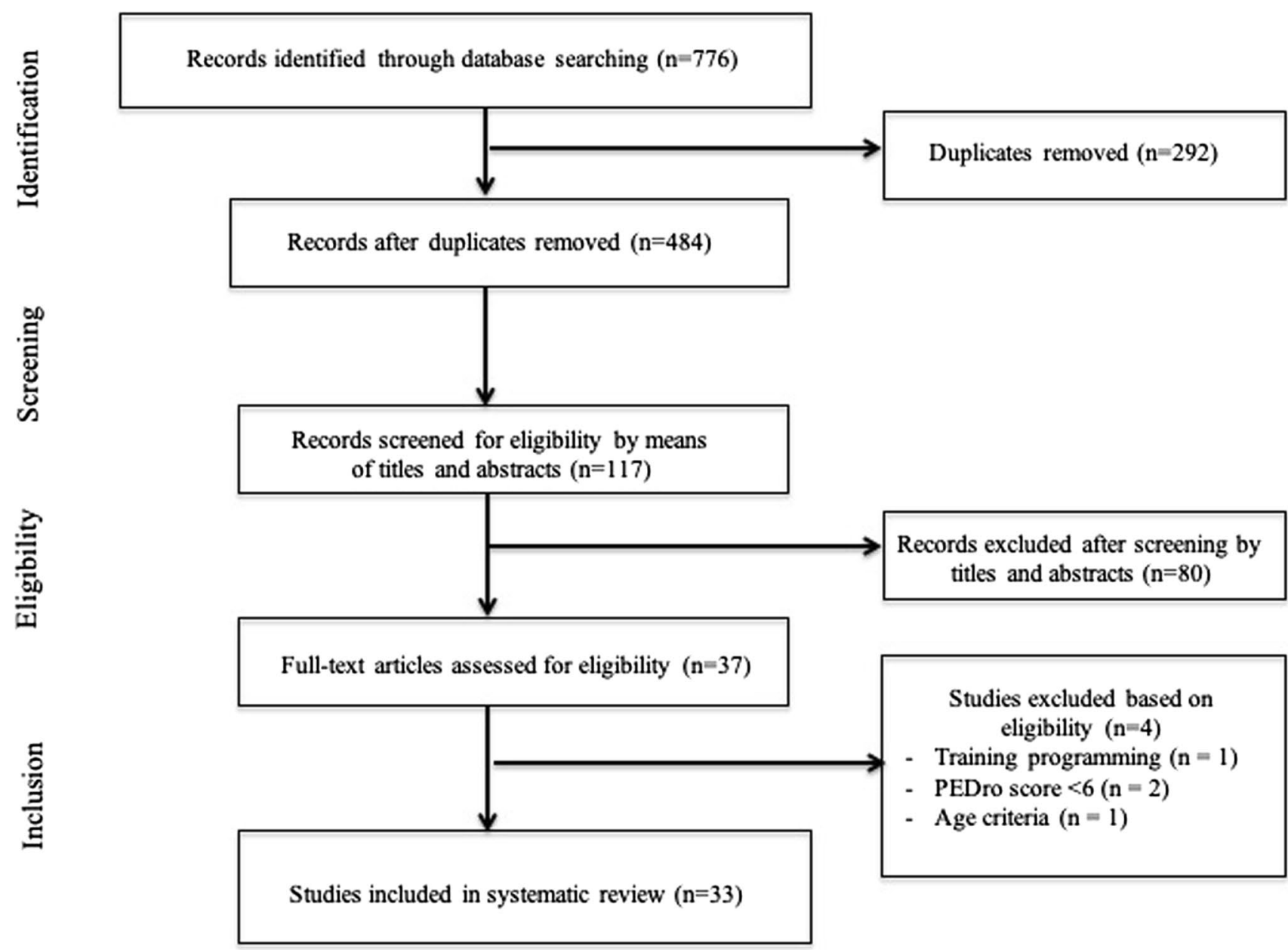

Fig. 1 Selection process for research articles $(n=33)$ included in this systematic review. Adapted version of the recommendations in the PRISMA (Preferred Reporting Items for Systematic Reviews and Meta-Analyses) statement [43] 
total score a trial could receive was limited to eight points. A cut-off of six points on the PEDro scale signified highquality studies, as this has been reported to be sufficient to determine high-quality versus low-quality studies [52]. The studies were evaluated by two experienced investigators (HZ and $\mathrm{AJ}$ ), and in the event of disagreement a third reviewer $(\mathrm{ACH})$ was invited to further review the findings.

\subsection{Data Analysis}

The percent change ( $\Delta \%$ ) was calculated (if not available in the study) for each study to evaluate the magnitude of the effects using the following equation:

$\Delta \%=($ Mpost - Mpre $) /$ Mpre $\times 100$

where Mpost represents the mean value after (acute exercise or long-term of training) and Mpre represents the baseline mean value.

Effect sizes (ES) were computed to present standardized effects of acute and long-term training on the outcome variables (e.g., hormones and physical performance). The ES was calculated with Cohen's $d$ [53] by dividing the raw ES (difference in means) by the pooled standard deviations:

$\mathrm{ES}=($ Cohen's $d)=(M 1-M 2) / \mathrm{SD}$ pooled $]$

Values for ES were defined as trivial $(<0.2)$, small $(0.2-0.6)$, moderate $(0.6-1.2)$, large $(1.2-2.0)$ and very large $>2$ [54]. Results for each outcome variable are presented with number of observations $(N), \Delta \%$ and ES. Data analysis was processed using SigmaStat 3.5 software (Systat, Inc, San Jose, CA, USA). The ES and $\Delta \%$ were analysed in studies where sufficient data were available. A significant difference was indicated when the $95 \%$ confidence interval (CI) of the ES did not overlap zero.

\section{Results}

\subsection{Study Selection}

Our search identified 484 studies related to the effects of exercise on hormone levels in adults over 40 years of age (Fig. 1). After screening of titles, abstracts and full texts, 33 studies were selected for inclusion in our final analysis, and the characteristics of these long-term studies are summarised in Table 2. The 33 studies were carried out in different countries from five continents (Africa, North America, Europe, Asia and Australia). Fifteen studies investigated only male subjects, ten studied female subjects exclusively, while eight studies investigated both males and females.

A total of 2211 participants (age range $=40-85$ years) underwent exercise-training programs and completed the studies. The 33 studies used different exercise-training protocols, with nine studies using endurance-training programs, ten studies examining the effects of high-intensity interval training (HIIT) and 14 studies investigating the effects of resistance training. The training duration lasted at least 2 weeks [4], but several studies used $\sim 12$ weeks, and four studies used a 52-week exercise protocol $[55,56]$. Studies were generally classified as 'high-quality' studies (mean 6.9 in the PEDro scale score) (Table 3).

\subsection{Total Testosterone}

Twelve studies investigated the effects of training on testosterone concentrations in older adults [16, 57-67] (Table 4). Irrespective of the exercise protocol (type of exercise, duration or intensity of exercise training), these studies all reported increases in basal total testosterone in both male and female participants (effect size: $0.19<d<3.37$, small to very large).

\subsection{Cortisol}

Nine studies investigated the effects of exercise training on cortisol in older adults (Table 5). Six studies reported increases in basal cortisol concentrations [15, 16, 58, 64, 67, 68] (effect size: $0.27<d<2.69$, small to very large), while three studies observed decreases [62, 63, 69] (effect size: $0.27<d<0.46$, small).

\subsection{Insulin}

The effects of long-term training on insulin concentrations in older adults are summarised in Table 6 . Nine studies [15, $64,65,70-74]$ reported decreased basal insulin (effect size: $0.04<d<2.30$, small to very large) and four studies [4, $69,75,76]$ observed increased concentrations (effect size: $0.32<d<0.56$, small).

\subsection{Insulin-Like Growth Factor-1 (IGF-1)}

Nine studies investigated the effects of training on IGF-1 concentrations in older adults (Table 7). Among these, eight studies reported significant increases in IGF-1 in both elderly males and females (effect size: $0.27<d<1.03$, small to moderate) $[65,66,69,72,77-80]$ and one study reported decreased IGF-1 [73] (effect size: 1.06).

\subsection{Sex Hormone-Binding Globulin (SHBG)}

Studies of the effects of training on SHBG concentrations in older adults are summarised in Table 8 . Six studies $[15,55$, 60-63] reported increases in basal SHBG concentrations in elderly women and men irrespective of the type, duration 
Table 2 Characteristics of studies that examined the effect of acute and chronic exercises on anabolic and catabolic hormones

\begin{tabular}{|c|c|c|c|c|c|c|c|c|}
\hline Study & Year & PEDro scale & $\begin{array}{l}\text { Population/sex/ } \\
\text { sample size }\end{array}$ & Sample size & Country & $\begin{array}{l}\text { Age, years } \\
(\text { mean } \pm S D) \text { or } \\
\text { age range }\end{array}$ & $\begin{array}{l}\text { Characteristics of } \\
\text { exercise training }\end{array}$ & $\begin{array}{l}\text { Duration } \\
\text { (weeks) }\end{array}$ \\
\hline $\begin{array}{l}\text { Friedenreih et al. } \\
\text { [69] }\end{array}$ & 2019 & 8 & $\begin{array}{l}\text { Post-menopausal } \\
\text { women }\end{array}$ & 396 & Canada & $59.4 \pm 4.9$ & $\begin{array}{l}\text { Moderate and high- } \\
\text { intensity training }\end{array}$ & 52 \\
\hline Vaczi et al. [59] & 2014 & 7 & Older men & 16 & Hungary & $65.7 \pm 5.3$ & $\begin{array}{l}\text { Stretch shortening } \\
\text { cycle and eccen- } \\
\text { tric training }\end{array}$ & 10 \\
\hline Im et al. [10] & 2019 & 7 & Older women & 25 & Korea & $69.4 \pm 2.9$ & $\begin{array}{l}\text { Yoga and Korean } \\
\text { dance }\end{array}$ & 12 \\
\hline Søgaard et al. [77] & 2018 & 6 & $\begin{array}{l}\text { Older men and } \\
\text { women }\end{array}$ & 22 & Denmark & $63 \pm 1$ & $\begin{array}{l}\text { High-intensity } \\
\text { interval training }\end{array}$ & 6 \\
\hline $\begin{array}{l}\text { Ahtiainen et al. } \\
\text { [60] }\end{array}$ & 2011 & 7 & Older men & 35 & Finland & $61 \pm 5$ & $\begin{array}{l}\text { Heavy resistance } \\
\text { exercise }\end{array}$ & 21 \\
\hline $\begin{array}{l}\text { Ahtiainen et al. } \\
\text { [61] }\end{array}$ & 2015 & 7 & Older men & 13 & Finland & $70 \pm 2$ & $\begin{array}{l}\text { Heavy resistance } \\
\text { exercise }\end{array}$ & 52 \\
\hline $\begin{array}{l}\text { Banitalebi et al. } \\
\text { [70] }\end{array}$ & 2018 & 9 & Older women & 48 & Iran & $67.4 \pm 1.4$ & $\begin{array}{l}\text { Resistance and } \\
\text { endurance train- } \\
\text { ing }\end{array}$ & 12 \\
\hline Consitt et al. [76] & 2016 & 7 & Young and older & 20 & USA & $19-29$ and $57-82$ & $\begin{array}{l}\text { Endurance and } \\
\text { strength training }\end{array}$ & 12 \\
\hline DiPietro et al. [63] & 2008 & 7 & Older women & 20 & USA & $77 \pm 6$ & $\begin{array}{l}\text { Aerobic training } \\
\text { and strength } \\
\text { training }\end{array}$ & 36 \\
\hline Glintborg et al. [62] & 2013 & 10 & Older males & 54 & Denmark & 68 & Strength training & 12 \\
\hline Ha et al. [72] & 2018 & 7 & Older women & 20 & North Korea & $73 \pm 2.8$ & $\begin{array}{l}\text { Combined resist- } \\
\text { ance training and } \\
\text { aerobic training }\end{array}$ & 12 \\
\hline Hayes et al. [63] & 2015 & 7 & Older men & 48 & Scotland & $61 \pm 5$ & $\begin{array}{l}\text { Low- to medium- } \\
\text { and high-intensity } \\
\text { training }\end{array}$ & 6 \\
\hline Hayes et al. [90] & 2015 & 6 & $\begin{array}{l}\text { Sedentary aged } \\
\text { men }\end{array}$ & 22 & UK & $62 \pm 2$ & $\begin{array}{l}\text { High-intensity } \\
\text { training }\end{array}$ & 6 \\
\hline Kim et al. [56] & 2017 & 7 & $\begin{array}{l}\text { Older men and } \\
\text { women }\end{array}$ & 555 & USA & 51 & $\begin{array}{l}\text { Moderate physical } \\
\text { activity }\end{array}$ & 52 \\
\hline Krishnan et al. [65] & 2013 & 7 & $\begin{array}{l}\text { Premenopausal } \\
\text { women }\end{array}$ & 28 & USA & $46.7 \pm 3.3$ & $\begin{array}{l}\text { Aerobic and resist- } \\
\text { ance training }\end{array}$ & 24 \\
\hline $\begin{array}{l}\text { Micielska et al. } \\
\text { [73] }\end{array}$ & 2019 & 6 & $\begin{array}{l}\text { Healthy inactive } \\
\text { women }\end{array}$ & 33 & Poland & $45 \pm 13$ & $\begin{array}{l}\text { High-intensity } \\
\text { circuit training }\end{array}$ & 5 \\
\hline Motiani et al. [55] & 2017 & 7 & $\begin{array}{l}\text { Sedentary men and } \\
\text { women }\end{array}$ & 26 & Finland & $45-55$ & $\begin{array}{l}\text { Moderate-intensity } \\
\text { interval training }\end{array}$ & 2 \\
\hline Nunes et al. [66] & 2019 & 7 & $\begin{array}{l}\text { Post-menopausal } \\
\text { women }\end{array}$ & 34 & Brazil & 64.2 & Resistance training & 16 \\
\hline Ogawa et al. [74] & 2010 & 6 & Older women & 21 & Japan & $85.0 \pm 4.5$ & Resistance training & 12 \\
\hline De Guia et al. [94] & 2019 & 6 & Older men & 43 & Denmark & $46.5 \pm 3.0$ & $\begin{array}{l}\text { Aerobic and resist- } \\
\text { ance training }\end{array}$ & 12 \\
\hline Praksch et al. [78] & 2019 & 7 & Older women & 60 & Hungary & $67.4 \pm 5$ & $\begin{array}{l}\text { Home-based walk- } \\
\text { ing and aerobic } \\
\text { training }\end{array}$ & 12 \\
\hline Ramos et al. [75] & 2016 & 7 & $\begin{array}{l}\text { Elderly men and } \\
\text { women }\end{array}$ & 66 & Australia & $58 \pm 7$ & $\begin{array}{l}\text { MICT and high- } \\
\text { intensity training }\end{array}$ & 16 \\
\hline Sato et al. [67] & 2014 & 6 & Older men & 19 & Japan & $67.2 \pm 1.8$ & Resistance training & 12 \\
\hline Sellami et al. [15] & 2016 & 7 & $\begin{array}{l}\text { Moderately trained } \\
\text { late adult men }\end{array}$ & 36 & Tunisia & $40.7 \pm 1.8$ & $\begin{array}{l}\text { Combined sprint } \\
\text { and resistance } \\
\text { training }\end{array}$ & 13 \\
\hline
\end{tabular}


Table 2 (continued)

\begin{tabular}{|c|c|c|c|c|c|c|c|c|}
\hline Study & Year & PEDro scale & $\begin{array}{l}\text { Population/sex/ } \\
\text { sample size }\end{array}$ & Sample size & Country & $\begin{array}{l}\text { Age, years } \\
(\text { mean } \pm S D) \text { or } \\
\text { age range }\end{array}$ & $\begin{array}{l}\text { Characteristics of } \\
\text { exercise training }\end{array}$ & $\begin{array}{l}\text { Duration } \\
\text { (weeks) }\end{array}$ \\
\hline Sellami et al. [16] & 2018 & 7 & $\begin{array}{l}\text { Moderately trained } \\
\text { late adult men }\end{array}$ & 40 & Tunisia & $40 \pm 2$ & $\begin{array}{l}\text { Combined sprint } \\
\text { and resistance } \\
\text { training }\end{array}$ & 13 \\
\hline Walker et al. [68] & 2015 & 7 & Older men & 18 & USA & $63.7 \pm 3$ & Resistance training & 20 \\
\hline Yamada et al. [79] & 2015 & 7 & $\begin{array}{l}\text { Community-dwell- } \\
\text { ing older men and } \\
\text { women }\end{array}$ & 222 & Japan & $76.3 \pm 5.9$ & $\begin{array}{l}\text { Walking exercise } \\
\text { and nutrition }\end{array}$ & 24 \\
\hline Bermon et al. [80] & 1999 & 6 & $\begin{array}{l}\text { Sedentary and } \\
\text { trained older } \\
\text { adults }\end{array}$ & 32 & France & $70.1 \pm 1$ & Strength training & 8 \\
\hline Bennefoy et al. [82] & 1999 & 6 & $\begin{array}{l}\text { Community-dwell- } \\
\text { ing older adults }\end{array}$ & 32 & France & $69.7 \pm 2.2$ & Physical activity & 2 \\
\hline Craig et al. [58] & 1989 & 6 & Older men & 9 & USA & $62.8 \pm 0.7$ & $\begin{array}{l}\text { Progressive resisted } \\
\text { exercise }\end{array}$ & 12 \\
\hline
\end{tabular}

PEDro scale physiotherapy evidence database scale, $F$ female, $M$ male, $M / F$ male and female, $x$ times, $W$ weeks, $H$ hour, min minutes, Others other methods of intervention beyond the physical activity, $B M I$ body mass index, $S D$ standard deviation

and intensity of exercise training (effect size: $0.25<d<1.68$, small to large).

\subsection{Growth Hormone (hGH)}

Only four studies investigated the effects of long-term training on basal hGH concentrations in older adults $[67,69,73$, 81] (Table 9). These studies reported increases in hGH in response to physical training (effect size: $0.29<d<2.58$, small to very large).

\subsection{Dehydroepiandrosterone (DHEA] and Dehydroepiandrosterone Sulfate (DHEA-S)}

Studies examining the effects of long-term training on basal DHEA concentrations in older adults are summarised in Table 10. Six studies $[10,55,64,66,78,82]$ reported increases in DHEA in older males and females (effect size: $0.37<d<1.71$, small to large). Only one study [65] reported a decrease (effect size: 0.28, small) in DHEA in post-menopausal women in response to 16 weeks of resistance training.

\section{Discussion}

This systematic review indicates that exercise training increases basal total testosterone, IGF-1, SHBG, hGH, DHEA and DHEA-S in males and females $\geq 40$ years of age. Effects of exercise on blood hormones occurred regardless of the type, duration and intensity of training programs, with the exception of a lack of consensus on the effects of long-term exercise training on cortisol and insulin responses in older adults (Fig. 2).

\subsection{Effect of Exercise on Testosterone Levels}

Exercise tended to produce small to large increases in total testosterone, supporting the supposition that exercise is the most convenient non-pharmacological means of increasing testosterone production and concomitantly preventing muscle loss in the elderly [60]. Different forms of exercise training can increase testosterone [60], although this finding is not ubiquitous $[32,83]$. For example, 6 weeks of progressive resistance exercise increased muscle testosterone levels in the elderly, due to increased muscle steroidogenesis [66]. This corresponded to increased blood free testosterone, although total testosterone was not reported as commonly measured by other investigations, which may explain the divergency of results. Herbert et al. [33] previously reported that exercise increased free testosterone but not total testosterone levels [33]. Preconditioning exercise (10\% increase) and HIIT (7\% increase) combined to increase total testosterone by $17 \%$ in previously sedentary males, but only increased free testosterone by $5 \%$ [63]. Thus, the fraction of testosterone measured may result in different findings between studies, as supported by a recent meta-analysis of exercise-induced testosterone changes that concluded that free testosterone, rather than total testosterone, was more likely to change following resistance exercise [83].

The findings of this systematic review suggest exercise increases blood testosterone in both males and females, although several studies suggest men were more likely to benefit from exercise training in terms of increased total 


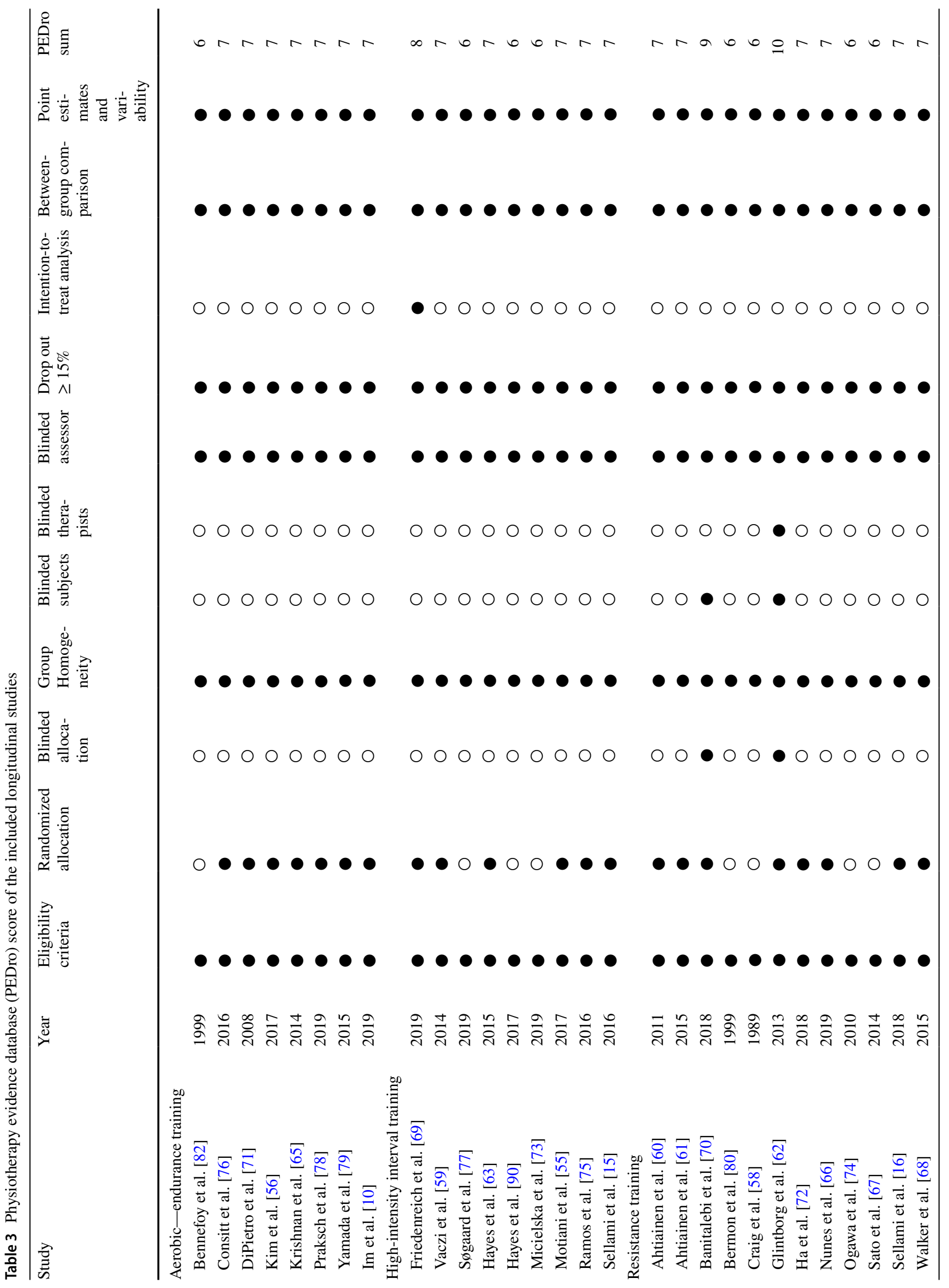


Table 4 Effects of training on total testosterone concentrations in elderly people

\begin{tabular}{|c|c|c|c|c|c|c|}
\hline \multirow[t]{2}{*}{ Reference(s) } & \multirow[t]{2}{*}{ Year } & \multirow[t]{2}{*}{ Intervention } & \multicolumn{2}{|l|}{ Population } & \multirow[t]{2}{*}{ Outcomes } & \multirow[t]{2}{*}{ Effect size } \\
\hline & & & Age & Sex & & \\
\hline Ahtiainen et al. [60] & 2011 & Heavy resistance exercise & $61 \pm 5$ & Male & Testosterone $\uparrow$ & 0.38 \\
\hline Ahtiainen et al. [61] & 2015 & Heavy resistance exercise & $70 \pm 2$ & Male & Testosterone $\uparrow$ & 1.99 \\
\hline Craig et al. [58] & 1989 & Progressive resistance training & $62.8 \pm 0.7$ & Male & Testosterone $\uparrow$ & 0.40 \\
\hline Glintborg et al. [62] & 2013 & Strength training & $68-78$ & Male & Testosterone $\uparrow$ & 0.90 \\
\hline Hayes et al. [63] & 2015 & Low to medium and high intensity training & $61 \pm 5$ & Male & Testosterone $\uparrow$ & 0.22 \\
\hline Hayes et al. [90] & 2015 & High-intensity interval training & $62 \pm 2$ & Male & Testosterone $\uparrow$ & 0.24 \\
\hline Krishnan et al. [65] & 2014 & Aerobic and resistance training & $46.7 \pm 3.3$ & Female & Testosterone $\uparrow$ & 0.19 \\
\hline Nunes et al. [66] & 2019 & Resistance training & 64.2 & Female & Testosterone $\uparrow$ & 0.29 \\
\hline Sato et al. [67] & 2014 & Resistance training & $67.2 \pm 1.8$ & Male & Testosterone $\uparrow$ & 3.37 \\
\hline Sellami et al. [16] & 2018 & Combined sprint and resistance training & $40 \pm 2$ & Male & Testosterone $\uparrow$ & 1.60 \\
\hline Vaczi et al. [59] & 2014 & Stretch shortening cycle and eccentric training & $65.7 \pm 5.3$ & Male & Testosterone $\uparrow$ & 0.32 \\
\hline Walker et al. [68] & 2015 & Resistance training & $63.7 \pm 3$ & Male & Testosterone $\uparrow$ & 0.39 \\
\hline
\end{tabular}

$\uparrow$ Indicates increase, $\downarrow$ indicates decrease

Table 5 Effects of training on cortisol concentrations in elderly people

\begin{tabular}{|c|c|c|c|c|c|c|}
\hline \multirow[t]{2}{*}{ Reference(s) } & \multirow[t]{2}{*}{ Year } & \multirow[t]{2}{*}{ Intervention } & \multicolumn{2}{|l|}{ Population } & \multirow[t]{2}{*}{ Outcomes } & \multirow[t]{2}{*}{ Effect size } \\
\hline & & & Age & Sex & & \\
\hline Banitalebi et al. [70] & 2018 & Resistance and endurance training & $67.3 \pm 1.4$ & Female & Cortisol $\downarrow$ & 0.27 \\
\hline Friedenreich et al. [69] & 2019 & Moderate- and high-intensity training & $59.4 \pm 4.9$ & Female & $\begin{array}{l}\text { Cortisol } \uparrow \\
\text { Cortisone } \uparrow \\
\text { Corticosterone } \uparrow\end{array}$ & $\begin{array}{l}2.69 \\
0.61 \\
1.12\end{array}$ \\
\hline Hayes et al. [63] & 2015 & Low- to medium- and high-intensity training & $61 \pm 5$ & Male & Cortisol $\downarrow$ & 0.39 \\
\hline Hayes et al. [90] & 2015 & High-intensity training & $62 \pm 2$ & Male & Cortisol $\downarrow$ & 0.46 \\
\hline Nunes et al. [66] & 2019 & Resistance training & $64.2 \pm 1.2$ & Female & Cortisol $\uparrow$ & 0.31 \\
\hline Sellami et al. [15] & 2016 & High-intensity sprint training and strength training & $40.7 \pm 1.8$ & Male & Cortisol $\uparrow$ & 0.98 \\
\hline Sellami et al. [16] & 2018 & Combined sprint and resistance training & $40 \pm 2$ & Male & Cortisol $\uparrow$ & 0.27 \\
\hline Vaczi et al. [59] & 2014 & Stretch shortening cycle and eccentric training & $65.7 \pm 5.3$ & Male & Cortisol $\uparrow$ & 0.37 \\
\hline Walker et al. [68] & 2015 & Resistance training & $63.7 \pm 3$ & Male & Cortisol $\uparrow$ & 0.38 \\
\hline
\end{tabular}

$\uparrow$ Indicates increase, $\downarrow$ indicates decrease

testosterone [59-61, 63]. Yet, benefits of exercise training in both sexes stretch beyond steroidogenesis, and include effects such as muscle mass regeneration, weight loss, disability prevention and prevention of sarcopenia [64, 65]. Differences in exercise training, such as type, intensity, frequency and duration, can potentially affect testosterone levels and muscle mass, with exercise volume being a critical component [84]. Results from this review demonstrate different forms of exercise (such as resistance training, HIIT, aerobic training) aid in maintenance of blood testosterone levels and muscle mass of the elderly. Levels of free testosterone, representing the fraction available for tissue uptake, are increased by exercise when total testosterone levels increase with no changes in SHBG levels [16]. There is much interest in regulation of testosterone levels in the aged as low testosterone is associated with many non-communicable diseases such as diabetes [85], cardiovascular disease [86], Alzheimer's disease [87], dementia [88], obesity [89] and ultimately mortality [86]. Evidence of increases in circulating testosterone (particularly the free fraction) by non-pharmacological means (e.g., exercise) has important implications for patients and clinicians [66, 67, 90]. Nevertheless, it remains unclear if increases in blood testosterone through exercise: (a) exceed inherent analytical and biological variability [91], and (b) exert benefits on ageing physiology in addition to the other effects of exercise.

\subsection{Effects of Exercise on Cortisol}

The results of our analysis indicate that effect sizes have qualitative differences [i.e., the direction of the effect (increase or decrease)] in the various studies, ranging from 
Table 6 Effects of training on insulin concentrations in elderly people

\begin{tabular}{|c|c|c|c|c|c|c|}
\hline \multirow[t]{2}{*}{ Reference(s) } & \multirow[t]{2}{*}{ Year } & \multirow[t]{2}{*}{ Intervention } & \multicolumn{2}{|l|}{ Population } & \multirow[t]{2}{*}{ Outcomes } & \multirow[t]{2}{*}{ Effect size } \\
\hline & & & Age & Sex & & \\
\hline Banitalebi et al. [70] & 2018 & Resistance and endurance training & $67.3 \pm 1.4$ & Female & Insulin $\uparrow$ & 0.56 \\
\hline Consitt et al. [76] & 2016 & Endurance and strength training & $67 \pm 3.3$ & Male and female & Insulin $\uparrow$ & 0.32 \\
\hline DiPietro et al. [71] & 2008 & Aerobic training and strength training & $77 \pm 6$ & Female & Insulin $\downarrow$ & 0.08 \\
\hline Guia et al. [94] & 2019 & High intensity interval training & $62.3 \pm 4.1$ & Male & Insulin $\downarrow$ & 1.90 \\
\hline Ha et al. [72] & 2018 & Combined resistance training and aerobic training & $73.0 \pm 2.8$ & Female & Insulin $\downarrow$ & 0.22 \\
\hline Krishnan et al. [65] & 2014 & Aerobic and resistance training & $46.7 \pm 3.3$ & Female & Insulin $\downarrow$ & 0.79 \\
\hline Micielska et al. [73] & 2019 & High-intensity circuit training & $45 \pm 13$ & Female & Insulin $\downarrow$ & 0.34 \\
\hline Motiani et al. [55] & 2017 & $\begin{array}{l}\text { Moderate-intensity continuous training and high-intensity } \\
\text { training }\end{array}$ & $50.0 \pm 3.6$ & Male & Insulin $\uparrow$ & 0.22 \\
\hline Nunes et al. [66] & 2019 & Resistance training & $64.2 \pm 1$ & Female & Insulin $\downarrow$ & 0.29 \\
\hline Ogawa et al. [74] & 2010 & Resistance training & $85.0 \pm 4.5$ & Female & Insulin $\downarrow$ & 2.30 \\
\hline Ramos et al. [75] & 2016 & $\begin{array}{l}\text { Moderate-intensity continuous training and high-intensity } \\
\text { training }\end{array}$ & $58 \pm 7$ & Male and female & Insulin $\downarrow$ & 0.04 \\
\hline Sellami et al. [15] & 2016 & High-intensity sprint training and strength training & $40.7 \pm 1.8$ & Male & Insulin $\downarrow$ & 0.60 \\
\hline Søgaard et al. [77] & 2019 & High-intensity interval training & $63 \pm 1$ & Male and female & Insulin $\uparrow$ & 0.32 \\
\hline
\end{tabular}

$\uparrow$ Indicates increase, $\downarrow$ indicates decrease

Table 7 Effects of training on insulin-like growth factor-1 (IGF-1) concentrations in elderly people

\begin{tabular}{|c|c|c|c|c|c|c|}
\hline \multirow[t]{2}{*}{ Reference(s) } & \multirow[t]{2}{*}{ Year } & \multirow[t]{2}{*}{ Intervention } & \multicolumn{2}{|l|}{ Population } & \multirow[t]{2}{*}{ Outcomes } & \multirow[t]{2}{*}{ Effect size } \\
\hline & & & Age & Sex & & \\
\hline Banitalebi et al. [70] & 2018 & Resistance and endurance training & $67.3 \pm 1.4$ & Female & IGF-1 $\uparrow$ & 0.27 \\
\hline Bennefoy et al. [82] & 1999 & Physical activity & $69.7 \pm 2.2$ & Male and female & IGF-1 $\uparrow$ & 0.46 \\
\hline Bermon et al. [80] & 1999 & Resistance training & $70.1 \pm 1.0$ & Male and female & IGF-1 $\uparrow$ & 0.97 \\
\hline Micielska et al. [73] & 2019 & High-intensity circuit training & $45 \pm 13$ & Female & IGF-1 $\uparrow$ & 0.32 \\
\hline Nunes et al. [66] & 2019 & Resistance training & 64.2 & Female & IGF-1 $\uparrow$ & 0.26 \\
\hline Ogawa et al. [74] & 2010 & Resistance training & $85.0 \pm 4.5$ & Female & IGF-1 $\downarrow$ & 1.06 \\
\hline Praksch et al. [78] & 2019 & Home-based walking and aerobic training & $67.4 \pm 5$ & Female & IGF-1 $\uparrow$ & 0.28 \\
\hline Sato et al. [67] & 2014 & Resistance training & $67.2 \pm 1.8$ & Male & IGF-1 $\uparrow$ & 1.03 \\
\hline Yamada et al. [79] & 2015 & Walking exercise and nutrition & $76.3 \pm 5.9$ & Male and female & $\mathrm{IGF}-1 \uparrow$ & 0.51 \\
\hline
\end{tabular}

$\uparrow$ Indicates increase, $\downarrow$ indicates decrease

Table 8 Effects of training on sex hormone-binding globulin (SHBG) concentrations in elderly people

\begin{tabular}{|c|c|c|c|c|c|c|}
\hline \multirow[t]{2}{*}{ Reference(s) } & \multirow[t]{2}{*}{ Year } & \multirow[t]{2}{*}{ Intervention } & \multicolumn{2}{|c|}{ Population } & \multirow[t]{2}{*}{ Outcomes } & \multirow[t]{2}{*}{ Effect size } \\
\hline & & & Age & Sex & & \\
\hline Ahtiainen et al. [61] & 2015 & Heavy resistance exercise & $70 \pm 2$ & Male & $\mathrm{SHBG} \uparrow$ & 0.25 \\
\hline Glintborg et al. [62] & 2013 & Strength training & 68 & Male & SHBG $\uparrow$ & 0.32 \\
\hline Hayes et al. [63] & 2015 & Low- to medium- and high-intensity training & $61 \pm 5$ & Male & $\mathrm{SHBG} \uparrow$ & 0.38 \\
\hline Hayes et al. [90] & 2017 & High-intensity training & $62 \pm 2$ & Male & SHBG $\uparrow$ & 0.43 \\
\hline Kim et al. [56] & 2017 & Moderate physical activity & 51 & Male and female & SHBG $\uparrow$ & 0.32 \\
\hline Sellami et al. [16] & 2018 & Combined sprint and resistance training & $40 \pm 2$ & Male & $\mathrm{SHBG} \uparrow$ & 1.68 \\
\hline
\end{tabular}

$\uparrow$ Indicates increase, $\downarrow$ indicates decrease 
Table 9 Effects of training on human growth hormone (hGH) concentrations in elderly people

\begin{tabular}{|c|c|c|c|c|c|}
\hline \multirow[t]{2}{*}{ Reference(s) } & \multirow[t]{2}{*}{ Intervention } & \multicolumn{2}{|l|}{ Population } & \multirow[t]{2}{*}{ Outcomes } & \multirow[t]{2}{*}{ Effect size } \\
\hline & & Age & Sex & & \\
\hline Banitaleb et al. [70] & Resistance and endurance training & $67.3 \pm 1.4$ & Female & $\mathrm{GH} \uparrow$ & 2.58 \\
\hline Craig et al. [58] & Progressive resistance training & $62.8 \pm 0.7$ & Male & $\mathrm{GH} \uparrow$ & 0.34 \\
\hline Im et al. [10] & Yoga and Korean dance & $69.3 \pm 2.9$ & Female & $\mathrm{GH} \uparrow$ & 0.74 \\
\hline Walker et al. [68] & Resistance training & $63.7 \pm 3$ & Male & $\mathrm{GH} \uparrow$ & 0.29 \\
\hline
\end{tabular}

$\uparrow$ Indicates increase, $\downarrow$ indicates decrease

Table 10 Effects of training on dehydroepiandrosterone (DHEA) and dehydroepiandrosterone sulfate (DHEA-S) concentrations in elderly people

\begin{tabular}{|c|c|c|c|c|c|}
\hline \multirow[t]{2}{*}{ Reference(s) } & \multirow[t]{2}{*}{ Intervention } & \multicolumn{2}{|l|}{ Population } & \multirow[t]{2}{*}{ Outcomes } & \multirow[t]{2}{*}{ Effect size } \\
\hline & & Age & Sex & & \\
\hline Boxer et al. [83] & DHEA supplements, aerobics and yoga & $76.4 \pm 6.2$ & Female & DHEA-S $\uparrow$ & 1.37 \\
\hline Im et al. [10] & Yoga and Korean dance & $69.3 \pm 2.9$ & Female & DHEA-S $\uparrow$ & 0.98 \\
\hline Kim et al. [56] & Moderate physical activity & 51 & Male and female & DHEA-S $\uparrow$ & 0.37 \\
\hline Krishnan et al. [65] & Aerobic and resistance training & $46.7 \pm 3.3$ & Female & DHEA-S $\uparrow$ & 0.41 \\
\hline Nunes et al. [66] & Resistance training & 64 & Female & DHEA-S $\downarrow$ & 0.28 \\
\hline Sato et al. [67] & Resistance training & $67.2 \pm 1.8$ & Male & DHEA-S $\uparrow$ & 1.71 \\
\hline Yamada et al. [79] & Walking exercise and nutrition & $76.3 \pm 5.9$ & Male and female & DHEA-S $\uparrow$ & 0.55 \\
\hline
\end{tabular}

$\uparrow$ Indicates increase, $\downarrow$ indicates decrease

\section{Effects of exercise training observed in advanced age}

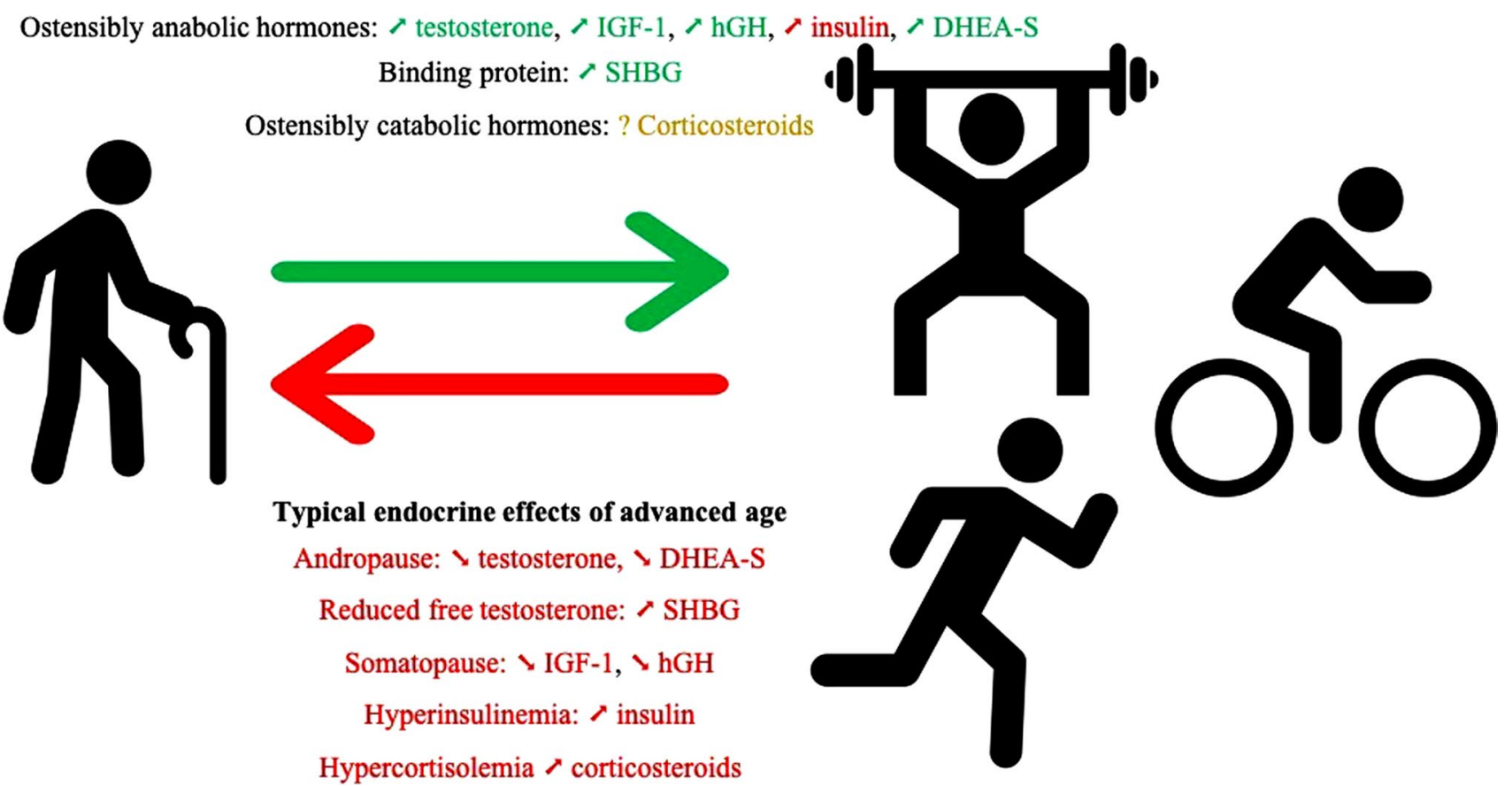

Fig. 2 Top: Summary of the main effects of exercise on hormones discussed in this review. Bottom: Summary of the main effects of ageing on hormones discussed in this review. $I G F-1$ insulin-like growth factor-1, $h G H$ human growth hormone, DHEA-S dehydroepiandrosterone sulfate, $S H B G$ sex hormone-binding globulin. $\pi$ indicates increase; $\forall$ indicates decrease 
a small decrease in cortisol to a very large increase, indicating an inconsistency in findings. Cortisol, corticosterone, cortisone and 11-deoxycortisol are key biomarkers of stress, particularly of acute stress [68]. Exercise training reduces stress in the elderly and often decreases basal cortisol and raises testosterone levels [58]. Recent studies report that post-training basal blood cortisol levels are decreased relative to non-exercise populations, and that exercise-induced changes in cortisol are unrelated to the volume, type and duration of exercise [68, 69]. A study by Hayes et al. [63] reported no improvements in blood cortisol levels after 12 weeks of training (of which 6 weeks was HIIT), although other reports indicated that increases in blood cortisol levels are not related to the type of exercise. It is possible that a single exercise bout may not be sufficient to cause persistent changes in adrenal function; however, benefits are likely if the exercise intensity is sufficient ( $60 \%$ maximal oxygen uptake), which is common in younger adults [15]. Another possibility is that age-related changes in the hypothalamuspituitary axis may alter responses to exercise [14].

\subsection{Effect of Exercise on DHEA and DHEA-S}

Small to very large increases of DHEA and DHEA-S posttraining were generally observed in our analysis, although the number of studies was relatively small. Men's DHEA-S responses were also greater than those of women [55]. DHEA levels decreased around 65 years of age and were associated with reduced muscle strength in males but not in females [81]. However, a significant decline in the circulating androgen DHEA-S between the ages 20 and 50 years was associated with the normal ageing process for women [64]. We observed that exercise tends to maintain blood levels of DHEA in both men and women. Even a single bout of exercise has demonstrated immediate increases in circulating androgen levels (testosterone and DHEA-S) [64]. DHEA hormonal levels are in general positively correlated with normal physical activity, involvement in sport and aerobic ability [93]. The effects of exercise training on DHEA-S levels differ in males and females [55]. Several studies have shown that serum DHEA levels in older adults are increased significantly by exercise training $[66,78]$. Recent evidence suggests that increased levels of DHEA-S during the menopausal transition can double cardiovascular disease risk and diabetes mellitus [10].

\subsection{Effect of Exercise on Insulin}

We found that exercise training reduces blood insulin levels in older adults in most studies, with four studies showing small to moderate increases [55, 70, 76, 77]. Effect sizes ranged from small to very large, with some variability in the findings. These divergent effects did not seem to be related to study duration, as those studies with the largest positive effects $[73,91]$ were only 12 weeks in duration. This corroborates a recent study [94] in which no changes were noted to insulin levels measured after 12 weeks of training in lifelong exercisers or lifelong sedentary older adults. Small to moderate effects were observed in the previously sedentary group only, suggesting that participant selection may have contributed to the variability we found. Insulin sensitivity decreases with age and can lead to insulin resistance and type 2 diabetes mellitus [70,75]. Skeletal muscle dysfunction and disuse associated with ageing is a primary cause of impaired glucose absorption and reduced mitochondrial oxidation [75]. Skeletal muscles are responsible for $>60 \%$ of glucose metabolism [72], and thus exercise in older adults is an important regulator of glucose metabaolism. HIIT improves insulin sensitivity, body composition and cardiovascular health [76], and several studies suggest the increase in insulin sensitivity due to exercise training is directly proportional to exercise intensity and volume [70,71], although there is also evidence that combined training may be more efficacious than one form of training alone [64, 69-71].

\subsection{Effect of Exercise on IGF-1}

Levels of IGF-1 were ubiquitously increased in the all the studies we analysed, with small to large effect sizes being evident. IGF-1 plays an important role in muscle development and insulin sensitivity [65], and changes in IGF-1 are correlated with cardiovascular disease risk and mortality [77]. IGF-1 levels decrease during ageing (i.e., the somatopause), but several exercise types can affect the synthesis of IGF-1 [65, 66, 72, 77]. Increased IGF-1 levels cause downstream improvements in insulin activity [65, 66, 77]. Resistance training reportedly causes greater increases in IGF-1 relative to endurance training $[65,69]$. Combined training with different exercise sequences did not affect IGF-1 [69]. When comparing concurrent training with interval training, concurrent training produced greater increases in IGF-1 levels [69]. Yet, high-intensity circuit training also produced significant elevations of IGF-1 that were accompanied by improvements in the homeostatic model assessment index of insulin resistance (HOMA1-IR) [72]. One important issue to consider from these data is the interpretation of increased IGF-1 levels. For example, Herbert et al. [33] reported increased IGF-1 following HIIT in previously sedentary older masters athletes, who had higher levels of IGF-1 than sedentary individuals, causing these authors to propose increased IGF-1 in older men was a positive physiological adaptation. Conversely, Hayes et al. [95] concluded IGF-1 decreases were a positive physiological adaptation following resistance training. These authors hypothesized that IGF-1 entered muscle tissue to exert downstream hypertrophic effects during periods of muscle building (i.e., anabolism). 
Muscle hypertrophy is not the only response to perturbations in IGF-1, with other effects of IGF-1 possible in participants who exercise.

\subsection{Effect of Exercise on SHBG}

Our analysis indicates that levels of SHBG in older adults were universally increased by exercise. This glycoprotein binds to androgens and oestrogens and its levels increase with age whilst testosterone decreases, resulting in lower levels of bioavailable and free testosterone available for biological effects following tissue uptake. Therefore, it is imperative to measure both SHBG and testosterone levels to obtain a better understanding of androgenic status. In this context, Hayes et al. [63] previously reported increases in total testosterone and SHBG levels, with no alterations in free testosterone levels [62]. There were larger increases in total testosterone SHBG when HIIT was used as the exercise protocol, suggesting increases in free testosterone [63]. Therefore, it is important to distinguish which hormone fraction is being measured in such studies. Low SHBG suggests a high androgenic nature in women, which is inversely related with adiposity and SHBG levels [55].

\subsection{Effect of Exercise on Human Growth Hormone}

We found only four studies that measured $\mathrm{hGH}$, all which reported increases in hGH having effect sizes from small to very large $[10,58,68,70]$. One possible reason for the limited number of studies measuring hGH may be its short biological half-life, making it more pragmatic to measure IGF-1, the main downstream protein of hGH secretion [68]. When comparing other forms of exercise, resistance training causes the largest increases in hGH levels in older adults [67]. Ageing accelerates the reduction of hGH secretion in both sexes, with females experiencing steeper declines than males [67, 69, 77]. Combined exercise programs such as resistance and endurance increase hGH levels [69].

\section{Conclusion}

In conclusion, exercise increases the levels of anabolic hormones in older adults, although the clinical significance of these alterations remains uncertain. It is apparent that exercise exerts anti-ageing effects on several physiological systems, but whether these effects are mediated by the endocrine system is unclear at this time. Nonetheless, we recommend that exercise should be considered as a first-line treatment for endocrine dysfunction as it improves several changes of the hormonal regulation that occur with ageing. Future investigations may wish to address the effects of exercise on hormonal concentrations in middle-aged individuals as this is typically where age-associated hormonal milieu alterations may begin to manifest. In the present review, regrettably we found that too few original articles were conducted in participants aged $40-60$ years, so additional articles in this age category would have allowed us to examine age differences and would have permitted practical applications for each age category.

Data Availability Statement All data supporting the findings of this study are available in this published article.

\section{Declarations}

Funding No sources of funding were used to assist in the preparation of this article.

Conflicts of Interest Hassane Zouhal, Ayyappan Jayavel, Kamalanathan Parasuraman, Lawrence D Hayes, Claire Tourny, Fatma Rhibi, Ismail Laher, Abderraouf Ben Abderrahman and Anthony C. Hackney declare that they have no conflicts of interest relevant to the content of this review.

Author Contributions Hassane Zouhal was involved in the conceptualization of the study, data analysis and writing the manuscript. Ayyappan Jayavel, Kamalanathan Parasuraman, Lawrence D. Hayes, Claire Tourny, Fatma Rhibi, Ismail Laher, Abderraouf Ben Abderrahman and Anthony C. Hackney were involved in the data assessment, data analysis and writing the manuscript. All authors approved the final version of the manuscript.

Open Access This article is licensed under a Creative Commons Attribution 4.0 International License, which permits use, sharing, adaptation, distribution and reproduction in any medium or format, as long as you give appropriate credit to the original author(s) and the source, provide a link to the Creative Commons licence, and indicate if changes were made. The images or other third party material in this article are included in the article's Creative Commons licence, unless indicated otherwise in a credit line to the material. If material is not included in the article's Creative Commons licence and your intended use is not permitted by statutory regulation or exceeds the permitted use, you will need to obtain permission directly from the copyright holder. To view a copy of this licence, visit http://creativecommons.org/licenses/by/4.0/.

\section{References}

1. Frontera WR, Hughes VA, Lutz KJ, Evans WJ. A cross-sectional study of muscle strength and mass in 45- to 78-yr-old men and women. J Appl Physiol Bethesda Md 1985. 1991;71(2):644-50.

2. Fleg JL, Lakatta EG. Role of muscle loss in the age-associated reduction in $V \mathrm{O}_{2}$ max. J Appl Physiol Bethesda Md 1985. 1988;65(3):1147-51.

3. Conley KE, Cress ME, Jubrias SA, Esselman PC, Odderson IR. From muscle properties to human performance, using magnetic resonance. J Gerontol A Biol Sci Med Sci. 1995;50:35-40.

4. Korhonen MT, Cristea A, Alén M, Häkkinen K, Sipilä S, Mero A, et al. Aging, muscle fiber type, and contractile function in sprint-trained athletes. J Appl Physiol Bethesda Md 1985. 2006;101(3):906-17.

5. Lexell J, Taylor CC, Sjöström M. What is the cause of the ageing atrophy? Total number, size and proportion of different fiber types 
studied in whole vastus lateralis muscle from 15- to 83-year-old men. J Neurol Sci. 1988;84(2-3):275-94.

6. Kundert AML, Nikolaidis PT, Di Gangi S, Rosemann T, Knechtle B. Changes in jumping and throwing performances in age-group athletes competing in the European Masters Athletics Championships between 1978 and 2017. Int J Environ Res Public Health. 2019;16(7):1200.

7. Galloway MT, Jokl P. Aging successfully: the importance of physical activity in maintaining health and function. $\mathrm{J}$ Am Acad Orthop Surg. 2000;8(1):37-44.

8. Proctor DN, Balagopal P, Nair KS. Age-related sarcopenia in humans is associated with reduced synthetic rates of specific muscle proteins. J Nutr. 1998;128(2 Suppl):351S-355S.

9. Lexell J, Henriksson-Larsén K, Winblad B, Sjöström M. Distribution of different fiber types in human skeletal muscles: effects of ageing studied in whole muscle cross sections. Muscle Nerve. 1983;6(8):588-95.

10. Im JY, Bang HS, Seo DY. The effects of 12 weeks of a combined exercise program on physical function and hormonal status in elderly Korean women. Int J Environ Res Public Health. 2019;16(21):4196.

11. Mayhew AJ, Griffith LE, Gilsing A, Beauchamp MK, Kuspinar A, Raina P. The association between self-reported and performancebased physical function with activities of daily living disability in the Canadian longitudinal study on aging. J Gerontol A Biol Sci Med Sci. 2020;75(1):147-54.

12. van den Beld AW, Kaufman J-M, Zillikens MC, Lamberts SWJ, Egan JM, van der Lely AJ. The physiology of endocrine systems with ageing. Lancet Diabetes Endocrinol. 2018;6(8):647-58.

13. Velez MP, Rosendaal N, Alvarado B, da Câmara S, Belanger E, Pirkle CM. Data on the association between age at natural menopause and physical function in older women from the International Mobility in Aging Study (IMIAS). Data Brief. 2019;23: 103811.

14. Hermann M, Berger P. Hormonal changes in ageing men: a therapeutic indication? Exp Gerontol. 2001;36(7):1075-82.

15. Sellami M, Ben Abderrahman A, Kebsi W, De Sousa MV, Zouhal $\mathrm{H}$. Original research: effect of sprint and strength training on glucoregulatory hormones: effect of advanced age. Exp Biol Med. 2017;242(1):113-23.

16. Sellami M, Dhahbi W, Hayes LD, Kuvacic G, Milic M, Padulo J. The effect of acute and chronic exercise on steroid hormone fluctuations in young and middle-aged men. Steroids. 2018;132:18-24.

17. Häkkinen K, Pakarinen A. Muscle strength and serum testosterone, cortisol and SHBG concentrations in middle-aged and elderly men and women. Acta Physiol Scand. 1993;148(2):199-207.

18. Matsumoto AM, Marck BT, Gruenewald DA, Wolden-Hanson T, Naai MA. Aging and the neuroendocrine regulation of reproduction and body weight. Exp Gerontol. 2000;35(9-10):1251-65.

19. Janssen JAMJL. Impact of physical exercise on endocrine aging. Front Horm Res. 2016;47:68-81.

20. Cao JJ, Kurimoto P, Boudignon B, Rosen C, Lima F, Halloran BP. Aging impairs IGF-I receptor activation and induces skeletal resistance to IGF-I. J Bone Miner Res. 2007;22(8):1271-9.

21. Mao K, Quipildor GF, Tabrizian T, Novaj A, Guan F, Walters RO, et al. Late-life targeting of the IGF-1 receptor improves healthspan and lifespan in female mice. Nat Commun. 2018;9(1):2394.

22. Hickson RC, Czerwinski SM, Falduto MT, Young AP. Glucocorticoid antagonism by exercise and androgenic-anabolic steroids. Med Sci Sports Exerc. 1990;22(3):331-40.

23. Kim YC. Testosterone supplementation in the ageing male. Int $\mathrm{J}$ Impot Res. 1999;11(6):343-52.

24. Lee DK, Chang C. Expression and degradation of androgen receptor: mechanism and clinical implication. J Clin Endocrinol Metab. 2003;88(9):4043-54.

25. Dunn JF, Nisula BC, Rodbard D. Transport of steroid hormones: binding of 21 endogenous steroids to both testosterone-binding globulin and corticosteroid-binding globulin in human plasma. $\mathrm{J}$ Clin Endocrinol Metab. 1981;53(1):58-68.

26. Goldman AL, Bhasin S, Wu FCW, Krishna M, Matsumoto AM, Jasuja R. A reappraisal of testosterone's binding in circulation: physiological and clinical implications. Endocr Rev. 2017;38(4):302-24.

27. Gruenewald DA, Matsumoto AM. Testosterone supplementation therapy for older men: potential benefits and risks. J Am Geriatr Soc. 2003;51(1):101-15.

28. Corpas E, Harman SM, Blackman MR. Human growth hormone and human aging. Endocr Rev. 1993;14(1):20-39.

29. Kim T, Chang JS, Kim H, Lee KH, Kong ID. Intense walking exercise affects serum IGF-1 and IGFBP3. J Lifestyle Med. 2015;5(1):21-5.

30. Strain T, Fitzsimons C, Kelly P, Mutrie N. The forgotten guidelines: cross-sectional analysis of participation in muscle strengthening and balance and co-ordination activities by adults and older adults in Scotland. BMC Public Health. 2016;16(1):1108.

31. Ari Z, Kutlu N, Uyanik BS, Taneli F, Buyukyazi G, Tavli T. Serum testosterone, growth hormone, and insulin-like growth factor- 1 levels, mental reaction time, and maximal aerobic exercise in sedentary and long-term physically trained elderly males. Int $\mathrm{J}$ Neurosci. 2004;114(5):623-37.

32. Nelson ME, Meredith CN, Dawson-Hughes B, Evans WJ. Hormone and bone mineral status in endurance-trained and sedentary postmenopausal women. J Clin Endocrinol Metab. 1988;66(5):927-33

33. Herbert P, Hayes LD, Sculthorpe NF, Grace FM. HIIT produces increases in muscle power and free testosterone in male masters athletes. Endocr Connect. 2017;6(7):430-6.

34. Rosety MÁ, Díaz AJ, Rosety JM, Pery MT, Brenes-Martín F, Bernardi M, et al. Exercise improved semen quality and reproductive hormone levels in sedentary obese adults. Nutr Hosp. 2017;34(3):603.

35. Mônico-Neto M, Antunes HKM, Dattilo M, Medeiros A, Souza HS, Lee KS, et al. Resistance exercise: a non-pharmacological strategy to minimize or reverse sleep deprivation-induced muscle atrophy. Med Hypotheses. 2013;80(6):701-5.

36. Ferreira CB, dos Teixeira PS, dos Santos GA, Maya ATD, do Brasil PA, Souza VC, et al. Effects of a 12-week exercise training program on physical function in institutionalized frail elderly. J Aging Res. 2018;2018: e7218102.

37. Geirsdottir OG, Arnarson A, Ramel A, Briem K, Jonsson PV, Thorsdottir I. Muscular strength and physical function in elderly adults 6-18 months after a 12-week resistance exercise program. Scand J Public Health. 2015;43(1):76-82.

38. Borst SE, Millard WJ, Lowenthal DT. Growth hormone, exercise, and aging: the future of therapy for the frail elderly. J Am Geriatr Soc. 1994;42(5):528-35.

39. Swift DL, Earnest CP, Blair SN, Church TS. The effect of different doses of aerobic exercise training on endothelial function in postmenopausal women with elevated blood pressure: results from the DREW study. Br J Sports Med. 2012;46(10):753-8.

40. Yasar Z, Elliott BT, Kyriakidou Y, Nwokoma CT, Postlethwaite $\mathrm{RD}$, Gaffney CJ, et al. Sprint interval training (SIT) reduces serum epidermal growth factor (EGF), but not other inflammatory cytokines in trained older men. Eur J Appl Physiol. 2021;121(7):1909-19.

41. Herbert P, Hayes LD, Beaumont AJ, Grace FM, Sculthorpe NF. Six weeks of high intensity interval training (HIIT) facilitates a four year preservation of aerobic capacity in sedentary older males: a reunion study. Exp Gerontol. 2021;15(150): 111373.

42. Pedisic Z, Shrestha N, Kovalchik S, Stamatakis E, Liangruenrom $\mathrm{N}$, Grgic J, et al. Is running associated with a lower risk of allcause, cardiovascular and cancer mortality, and is the more the 
better? A systematic review and meta-analysis. Br J Sports Med. 2020;54(15):898-905.

43. Chief Medical Officers of England Scotland, Wales, and Northern Ireland. Start active, stay active. A report on physical activity for health from the four home countries' Chief Medical Officers. London: Crown; 2011.

44. Elliott BT, Hayes LD, Hughes DC, Burtscher M. Editorial: exercise as a countermeasure to human aging. Front Physiol. 2020;11:883.

45. Elliott BT, Herbert P, Sculthorpe N, Grace FM, Stratton D, Hayes LD. Lifelong exercise, but not short-term high-intensity interval training, increases GDF11, a marker of successful ageing: a preliminary investigation. Physiol Rep. 2017;5(13): e13343.

46. Chodzko-Zajko WJ. Exercise and physical activity for older adults. Kinesiol Rev. 2014;3(1):101-6.

47. Copeland JL. Exercise in older adults: the effect of age on exercise endocrinology. In: Hackney AC, Constantini NW, editors. Endocrinology of physical activity and sport (internet). Cham: Springer; 2020. p. 421-40. https://doi.org/10.1007/978-3-03033376-8_23.

48. Moher D, Shamseer L, Clarke M, Ghersi D, Liberati A, Petticrew $\mathrm{M}$, et al. Preferred reporting items for systematic review and meta-analysis protocols (PRISMA-P) 2015 statement. Syst Rev. 2015;4(1):1.

49. McTiernan A, Wu L, Chen C, Chlebowski R, Mossavar-Rahmani $\mathrm{Y}$, Modugno F, et al. Relation of BMI and physical activity to sex hormones in postmenopausal women. Obes Silver Spring Md. 2006;14(9):1662-77.

50. Higgins JPT, Thomas J, Chandler J, Cumpston M, Li T, Page MJ, Welch VA, editors. Cochrane handbook for systematic reviews of interventions version 6.2 (updated February 2021). Cochrane, 2021. Available from www.training.cochrane.org/handbook.

51. Liberati A, Altman DG, Tetzlaff J, Mulrow C, Gøtzsche PC, Ioannidis JPA, et al. The PRISMA statement for reporting systematic reviews and meta-analyses of studies that evaluate healthcare interventions: explanation and elaboration. BMJ. 2009;339:b2700.

52. Maher CG, Sherrington C, Herbert RD, Moseley AM, Elkins M. Reliability of the PEDro scale for rating quality of randomized controlled trials. Phys Ther. 2003;83(8):713-21.

53. Cohen J. Statistical power analysis for the behavioral sciences. 2nd ed. Hillsdale: L. Erlbaum Associates; 1988. p. 567.

54. Hopkins WG, Marshall SW, Batterham AM, Hanin J. Progressive statistics for studies in sports medicine and exercise science. Med Sci Sports Exerc. 2009;41(1):3-13.

55. Motiani KK, Savolainen AM, Eskelinen J-J, Toivanen J, Ishizu T, Yli-Karjanmaa M, et al. Two weeks of moderate-intensity continuous training, but not high-intensity interval training, increases insulin-stimulated intestinal glucose uptake. J Appl Physiol. 2017;122(5):1188-97.

56. Kim C, Dabelea D, Kalyani RR, Christophi CA, Bray GA, PiSunyer $\mathrm{X}$, et al. Changes in visceral adiposity, subcutaneous adiposity, and sex hormones in the diabetes prevention program. J Clin Endocrinol Metab. 2017;102(9):3381-9.

57. Hildreth KL, Barry DW, Moreau KL, Vande Griend J, Meacham $\mathrm{RB}$, Nakamura T, et al. Effects of testosterone and progressive resistance exercise in healthy, highly functioning older men with low-normal testosterone levels. J Clin Endocrinol Metab. 2013;98(5):1891-900.

58. Craig BW, Brown R, Everhart J. Effects of progressive resistance training on growth hormone and testosterone levels in young and elderly subjects. Mech Ageing Dev. 1989;49(2):159-69.

59. Váczi M, Nagy SA, Kőszegi T, Ambrus M, Bogner P, Perlaki G, et al. Mechanical, hormonal, and hypertrophic adaptations to 10 weeks of eccentric and stretch-shortening cycle exercise training in old males. Exp Gerontol. 2014;58:69-77.
60. Ahtiainen JP, Hulmi JJ, Kraemer WJ, Lehti M, Nyman K, Selänne $\mathrm{H}$, et al. Heavy resistance exercise training and skeletal muscle androgen receptor expression in younger and older men. Steroids. 2011;76(1-2):183-92.

61. Ahtiainen JP, Nyman K, Huhtaniemi I, Parviainen T, Helste M, Rannikko A, et al. Effects of resistance training on testosterone metabolism in younger and older men. Exp Gerontol. 2015;69:148-58.

62. Glintborg D, Christensen LL, Kvorning T, Larsen R, Brixen K, Hougaard DM, et al. Strength training and testosterone treatment have opposing effects on migration inhibitor factor levels in ageing men. Mediators Inflamm. 2013;2013:1-7.

63. Hayes LD, Grace FM, Baker JS, Sculthorpe N. Exercise-induced responses in salivary testosterone, cortisol, and their ratios in men: a meta-analysis. Sports Med. 2015;45(5):713-26.

64. Hayes LD, Herbert P, Sculthorpe NF, Grace FM. Exercise training improves free testosterone in lifelong sedentary ageing men. Endocr Connect. 2017;6(5):306-10.

65. Krishnan S, Gustafson MB, Campbell C, Gaikwad NW, Keim NL. Association between circulating endogenous androgens and insulin sensitivity changes with exercise training in midlife women. Menopause. 2014;21(9):967-74.

66. Nunes PRP, Barcelos LC, Oliveira AA, Furlanetto R, Martins FM, Resende EAMR, et al. Muscular strength adaptations and hormonal responses after two different multiple-set protocols of resistance training in postmenopausal women. J Strength Cond Res. 2019;33(5):1276-85.

67. Sato K, Iemitsu M, Matsutani K, Kurihara T, Hamaoka T, Fujita $\mathrm{S}$. Resistance training restores muscle sex steroid hormone steroidogenesis in older men. FASEB J. 2014;28(4):1891-7.

68. Walker S, Santolamazza F, Kraemer W, Häkkinen K. Effects of prolonged hypertrophic resistance training on acute endocrine responses in young and older men. J Aging Phys Act. 2015;23(2):230-6.

69. Friedenreich CM, Wang Q, Shaw E, Heer EV, Zhou R, Brenner $\mathrm{DR}$, et al. The effect of prescribed exercise volume on biomarkers of chronic stress in postmenopausal women: Results from the Breast Cancer and Exercise Trial in Alberta (BETA). Prev Med Rep. 2019;15: 100960.

70. Banitalebi E, Faramarzi M, Bagheri L, Kazemi AR. Comparison of performing 12 weeks' resistance training before, after and/or in between aerobic exercise on the hormonal status of aged women: a randomized controlled trial. Horm Mol Biol Clin Investig (Internet). 2018;35(3). http://www.degruyter.com/view/j/hmbci.2018. 35.issue-3/hmbci-2018-0020/hmbci-2018-0020.xml. Accessed 17 Aug 2020

71. DiPietro L, Yeckel CW, Dziura J. Progressive improvement in glucose tolerance following lower-intensity resistance versus moderate-intensity aerobic training in older women. J Phys Act Health. 2008;5(6):854-69.

72. Ha M-S, Son W-M. Combined exercise is a modality for improving insulin resistance and ageing-related hormone biomarkers in elderly Korean women. Exp Gerontol. 2018;114:13-8.

73. Micielska K, Gmiat A, Zychowska M, Kozlowska M, Walentukiewicz A, Lysak-Radomska A, et al. The beneficial effects of 15 units of high-intensity circuit training in women is modified by age, baseline insulin resistance and physical capacity. Diabetes Res Clin Pract. 2019;152:156-65.

74. Ogawa K, Sanada K, Machida S, Okutsu M, Suzuki K. Resistance exercise training-induced muscle hypertrophy was associated with reduction of inflammatory markers in elderly women. Mediators Inflamm. 2010;2010:1-7.

75. Ramos JS, Dalleck LC, Borrani F, Mallard AR, Clark B, Keating $\mathrm{SE}$, et al. The effect of different volumes of high-intensity interval training on proinsulin in participants with the metabolic syndrome: a randomised trial. Diabetologia. 2016;59(11):2308-20. 
76. Consitt LA, Saxena G, Saneda A, Houmard JA. Age-related impairments in skeletal muscle PDH phosphorylation and plasma lactate are indicative of metabolic inflexibility and the effects of exercise training. Am J Physiol Endocrinol Metab. 2016;311(1):E145-56.

77. Søgaard D, Baranowski M, Larsen S, Taulo Lund M, Munk Scheuer C, Vestergaard Abildskov C, et al. Muscle-saturated bioactive lipids are increased with aging and influenced by highintensity interval training. Int J Mol Sci. 2019;20(5):1240.

78. Praksch D, Sandor B, Kovacs D, Petrovics P, Kovacs K, Toth K, et al. Impact of home- and center- based physical training program on cardio-metabolic health and IGF-1 level in elderly women. Eur Rev Aging Phys Act. 2019;16(1):13.

79. Yamada M, Nishiguchi S, Fukutani N, Aoyama T, Arai H. Mailbased intervention for sarcopenia prevention increased anabolic hormone and skeletal muscle mass in community-dwelling Japanese older adults: the INE (intervention by nutrition and exercise) study. J Am Med Dir Assoc. 2015;16(8):654-60.

80. Bermon S, Ferrari P, Bernard P, Altare S, Dolisi C. Responses of total and free insulin-like growth factor-I and insulin-like growth factor binding protein-3 after resistance exercise and training in elderly subjects. Acta Physiol Scand. 1999;165(1):51-6.

81. Im JY, Bang HS, Seo DY. The effects of 12 weeks of a combined exercise program on physical function and hormonal status in elderly Korean women. Int J Environ Res Public Health. 2019;16(21):E4196.

82. Bonnefoy M, Kostka T, Patricot MC, Berthouze SE, Mathian B, Lacour JR. Influence of acute and chronic exercise on insulin-like growth factor-I in healthy active elderly men and women. Aging Clin Exp Res. 1999;11(6):373-9.

83. Boxer RS, Kleppinger A, Brindisi J, Feinn R, Burleson JA, Kenny AM. Effects of dehydroepiandrosterone (DHEA) on cardiovascular risk factors in older women with frailty characteristics. Age Ageing. 2010;39(4):451-8.

84. Vingren JL, Kraemer WJ, Ratamess NA, Anderson JM, Volek JS, Maresh CM. Testosterone physiology in resistance exercise and training: the up-stream regulatory elements. Sports Med Auckl NZ. 2010;40(12):1037-53.

85. Hayes LD, Elliott BT. Short-term exercise training inconsistently influences basal testosterone in older men: a systematic review and meta-analysis. Front Physiol. 2019;9:1878.
86. Khaled EB, Sami TA. Low testosterone and diabetes. Curr Diabetes Rev. 2013;9(5):418-21.

87. Yeap BB. Testosterone and cardiovascular disease risk. Curr Opin Endocrinol Diabetes Obes. 2015;22(3):193-202.

88. Lv W, Du N, Liu Y, Fan X, Wang Y, Jia X, et al. Low testosterone level and risk of Alzheimer's disease in the elderly men: a systematic review and meta-analysis. Mol Neurobiol. 2016;53(4):2679-84.

89. Carcaillon L, Brailly-Tabard S, Ancelin M-L, Tzourio C, FoubertSamier A, Dartigues J-F, et al. Low testosterone and the risk of dementia in elderly men: Impact of age and education. Alzheimers Dement J Alzheimers Assoc. 2014;10(5 Suppl):S306-314.

90. Hayes LD, Sculthorpe N, Herbert P, Baker JS, Spagna R, Grace FM. Six weeks of conditioning exercise increases total, but not free testosterone in lifelong sedentary ageing men. Aging Male. 2015;18(3):195-200.

91. Tissandier O, Péres G, Fiet J, Piette F. Testosterone, dehydroepiandrosterone, insulin-like growth factor 1 , and insulin in sedentary and physically trained aged men. Eur J Appl Physiol. 2001;85(1-2):177-84.

92. Hayes LD, Sculthorpe N, Young JD, Baker JS, Grace FM. Critical difference applied to exercise-induced salivary testosterone and cortisol using enzyme-linked immunosorbent assay (ELISA): distinguishing biological from statistical change. J Physiol Biochem. 2014;70(4):991-6.

93. Hayes LD, Sculthorpe N, Herbert P, Baker JS, Hullin DA, Kilduff LP, et al. Salivary testosterone measurement does not identify biochemical hypogonadism in ageing men: a ROC analysis. Endocrine. 2015;50(1):256-9.

94. de Guia RM, Agerholm M, Nielsen TS, Consitt LA, Søgaard D, Helge JW, et al. Aerobic and resistance exercise training reverses age-dependent decline in NAD+ salvage capacity in human skeletal muscle. Physiol Rep. 2019;7(12): e14139.

95. Hayes LD, Herbert P, Sculthorpe N, Grace F. High intensity interval training (HIIT) produces small improvements in fasting glucose, insulin, and insulin resistance in sedentary older men but not masters athletes. Exp Gerontol. 2020;15(140): 111074.

\section{Authors and Affiliations}

\section{Hassane Zouhal ${ }^{1,2}$ (1) $\cdot$ Ayyappan Jayavel ${ }^{3} \cdot$ Kamalanathan Parasuraman $^{3} \cdot$ Lawrence D. Hayes $^{4} \cdot$ Claire Tourny $^{5}$. Fatma Rhibi ${ }^{1}$. Ismail Laher ${ }^{6}$. Abderraouf Ben Abderrahman ${ }^{7}$. Anthony C. Hackney ${ }^{8}$}

Hassane Zouhal hassane.zouhal@univ-rennes2.fr

Anthony C. Hackney ach@email.unc.edu

1 M2S, Laboratoire Mouvement, Sport, Santé, EA 1274, Université Rennes, 35000 Rennes, France

2 Institut International des Sciences du Sport (2I2S), 35850 Irodouer, France

3 SRM College of Physiotherapy, SRM Institute of Science and Technology, SRM Nagar, Kattankulathur, Kanchipuram, Chennai, TN 603203, India
Institute of Clinical Exercise and Health Science, School of Health and Life Sciences, University of the West of Scotland, Lanarkshire Campus, Glasgow G72 0LH, UK

5 EA 3832 CETAPS, University of Rouen, Rouen, France

6 Faculty of Medicine, Department of Anesthesiology, Pharmacology and Therapeutics, The University of British Columbia, Vancouver, Canada

7 ISSEP Ksar-Said, University of La Manouba, Tunis, Tunisia

8 Department of Exercise and Sport Science, Department of Nutrition, University of North Carolina, Chapel Hill, NC, USA 